\title{
A USUCAPIÃO CONJUGAL NO DIREITO BRASILEIRO
}

\author{
Ana Cláudia Barbosa Proença de Brito \\ Aluna do curso de Direito da FA7. Artigo sob a orientação do \\ prof. Me. José Vander Tomaz Chaves (FA7). \\ claudiaproenca.acbp@gmail.com
}

SUMÁRIO: Introdução. 1. Noções Gerais de Propriedade. 2. A Usucapião Conjugal. 3. Das Principais Controvérsias acerca da Usucapião Conjugal. Considerações Finais. Referências.

Resumo: O tema do presente estudo guarda relação direta com um dos modos de aquisição da propriedade, qual seja, a usucapião. Por possuir diversas peculiaridades, decidiu o legislador criar modalidades para atender necessidades específicas. Entre essas várias modalidades, a usucapião conjugal ganhou destaque por ser a mais recente. Prevista no art. 1240-A do Código Civil (CC), essa modalidade possui diversos aspectos controversos e problemáticos. Objetivando analisar as atecnias e inconstitucionalidades que prejudicam a aplicabilidade de tal norma, fez-se ampla pesquisa doutrinária, principalmente em bibliotecas. Várias foram as críticas apresentadas, constatandose um entendimento predominante pela inconstitucionalidade do mencionado dispositivo legal e pela necessidade de adequada compreensão da terminologia empregada.

Palavras-chave: Função social. Abandono do lar. Propriedade. Usucapião familiar.

\section{INTRODUÇÃOO}

O programa "Minha Casa, Minha Vida" foi regulado pela Lei no 12.424/11, tendo esta, em seu artigo $9^{\circ}$, acrescido ao CC o art. 1240-A, o qual trata da usucapião conjugal.

Buscando uma maior aplicabilidade ao direito fundamental à moradia, o legislador fundamentou essa modalidade de usucapião na ideia de que, decorrido o prazo de dois anos, o cônjuge que permanecer no imóvel após de abandonado o lar pelo outro terá direito a usucapir a parte que não lhe cabia. Entretanto, tal instituto traz alguns requisitos peculiares os quais o tornam alvo de diversas discussões relacionadas a eventuais inconstitucionalidades e atecnias.

O uso da palavra "direta" no artigo supracitado do CC, a compreensão do que seria considerado abandono, a suposta afronta à $E C n^{\circ} 66 / 10$, o início da contagem do prazo, a possibilidade da efetivação da presente modalidade apenas aos imóveis urbanos e, ainda, o limite do uso do instituto a uma única vez são pontos amplamente debatidos no presente trabalho.

Nesse sentido, serão ressaltados os temas controversos, indicando, quando oportuno, considerações que tenham por objeto sanar as atecnias mais evidentes. 


\title{
1 Noções Gerais de Propriedade
}

A compreensão do instituto da usucapião conjugal está intrinsecamente ligada ao entendimento da propriedade privada. Assim, mister se faz que seja explanado o sentido adequado desta. No intuito de elucidar o mencionado tema, Pontes de Miranda (1955, p. 9) assim dispõe:

\begin{abstract}
Em sentido amplíssimo, propriedade é o domínio ou qualquer direito patrimonial. Tal conceito desborda o direito das coisas. O crédito é propriedade. Em sentido amplo, propriedade é todo direito irradiado em virtude de ter incidido regra de direito das coisas (CP, arts. 485, 524 e 862). Em sentido quase coincidente, é todo direito sobre as coisas corpóreas e a propriedade literária, científica, artística e industrial. Em sentido estritíssimo, é só o domínio.
\end{abstract}

A ideia de propriedade remonta ao homem primitivo, o qual já compreendia a necessidade de dominação para proteger seus objetos de caça, suas presas e seus territórios. A partir do desenvolvimento da concepção de domínio, os conflitos foram inevitáveis, visto que aquele era representante de poder.

Diante do choque de interesses, imprescindível era a criação de um sistema de controle. Para cumprir tal função, a norma foi o meio adequado e eficaz encontrado para a manutenção da ordem e a garantia de proteção dos bens que já estavam submetidos a domínio estável.

A esse respeito, nas lições de Pereira (2013, p. 67), observa-se que:

\begin{abstract}
A princípio foi o fato, que nasceu com a espontaneidade de todas as manifestações fáticas. Mais tarde foi a norma que o disciplinou, afeiçoando-a às exigências sociais e à harmonia da coexistência. Nasceu da necessidade de dominação. Objetos de uso e armas. Animais de presa e de tração. Terra e bens da vida. Gerou ambições e conflitos. Inspirou a disciplina. Suscitou a regra jurídica. Tem sido comunitária, familial, individual, mística, política, aristocrática, democrática, estatal, coletiva.
\end{abstract}

Entretanto, somente em Roma pôde-se encontrar o nascimento do instituto da propriedade, embora não se tenha elaborado um conceito específico. Com a invasão bárbara surgiu a fase feudal, em que a propriedade de grandes territórios foi destinada aos nobres, restando aos camponeses explorar pequenas porções de terras em troca da entrega de parte da sua produção ao seu senhor.

Com a eclosão das Revoluções Liberais, apregoou-se a autonomia da vontade, permitindo, assim, a aquisição de propriedade pelo empenho de cada indivíduo. A partir de então, o direito àquela adquiriu status constitucional e passou a contemplar o rol dos direitos fundamentais de primeira geração.

Coadunando com a concepção liberal, a Constituição Brasileira de 1988 traz previsão ao direito fundamental à propriedade especificando-o em seu art. $5^{\circ}$, caput e inciso XXII, os quais estabelecem que é garantido a todo brasileiro o direito à propriedade. Ante a constatação de tal previsão e da importância do instituto, Farias e Rosenvald (2012, p. 279) ensinam que:

\footnotetext{
O direito subjetivo de propriedade acaba por se firmar como o mais amplo de todos os direitos subjetivos patrimoniais. Há sólidos argumentos que mantêm o caráter fundamental do direito à propriedade. Para além de seu reconhecimento constitucional expresso, são inegáveis a sua imutabilidade formal e material e a judicialidade plena. É o direito real por excelência, em torno do qual gravita o direito das coisas. Com efeito, a propriedade é um direito fundamental que, ao lado dos calores da vida, liberdade, igualdade e segurança, compõe a norma do art. $5^{\circ}$, caput, da Constituição Federal.
}

Com o reconhecimento do caráter fundamental ao direito à propriedade, poder-se-ia supor que este seria exercido para satisfazer todos os caprichos do proprietário. O próprio art. 1228 
do CC facilita tal percepção, vez que cita a possibilidade de o proprietário usar, gozar e dispor do bem sobre o qual exerce seu direito, sem, no entanto, especificar claramente as obrigações que advenham deste; apenas apresenta o $\S 1^{\circ}$, o qual aborda de maneira imprecisa os deveres para o exercício responsável do poder de proprietário. Contudo, aquele que desfruta da propriedade deve observar a função social que esta atrai para si.

Função social é um termo de origem latina que deriva de function, ou seja, traduz-se pela finalidade inerente a determinado instituto jurídico.

Passou-se a compreender que os direitos individuais de um poderiam ferir os interesses da coletividade. O Direito, a partir de então, passou a resguardar as garantias sociais, não se permitindo que uma dada prerrogativa fosse exercida em detrimento do interesse público. A função social, assim, impõe que os direitos privados devem ser efetivados não para atender unicamente o interesse individual, mas, também, para prover as necessidades da coletividade.

Diante de tal princípio, o direito à propriedade incorporou seus fundamentos e passou a ser preconizada a necessidade de sua harmonização com os anseios sociais. Por conseguinte, compreende-se que tal direito traz em si um dever, qual seja exercer as prerrogativas de proprietário sem, no entanto, deflagrar resultados ilícitos e ofensivos à integridade social.

A partir do exposto, é possível verificar o adequado conceito de direito à propriedade, compreendendo este, conforme o art. 1228, caput, do CC, como o direito de usar, gozar e dispor da coisa, bem como reavê-la de quem injustamente a tenha tomado, de modo a coadunar-se o interesse do proprietário com o interesse coletivo.

"Usar" significa colocar o bem a serviço do proprietário, extraindo daquele a utilidade que lhe é peculiar. "Fruir" pressupõe extrair da coisa os frutos e produtos, entendendo-se estes como os bens gerados por outros bens. O produto, entretanto, difere do fruto pelo fato daquele não ser renovável. "Dispor" aborda a possibilidade de desfazer-se da propriedade, tornando-a alheia através da venda, troca, doação ou outro meio de transferência. O último elemento especificado pela lei é o rei vindicatio, qual seja a possibilidade de reaver o bem que foi indevidamente retirado.

A propriedade possui, além dos elementos já descritos, características peculiares. Assim, pode-se dizer que ela possui um caráter absoluto. Isso não quer dizer que se trata de um direito sem limites, mas que é oponível erga omnes, ou seja, é legítimo reclamá-lo contra qualquer pessoa que adentrar ou utilizar o imóvel sem autorização.

O direito à propriedade é pleno, isto é, todos os poderes inerentes à coisa estão nas mãos do proprietário sem que ninguém possa exercer nenhum direito real sobre esse bem. Esse direito ainda é caracterizado pela exclusividade, aspecto comum a todos os direitos reais e significa que se alguém é dono de um bem, ninguém mais poderá sê-lo. Outra peculiaridade importante é a perpetuidade. Isso não significa infinitude, pois se trata do desconhecimento do término de tal direito. Diniz (2013, p. 137) esclarece minuciosamente tal diferenciação:

\footnotetext{
Tal perpetuidade não significa que um bem deve pertencer sempre ao mesmo titular, visto que os homens duram, em regra, menos do que seus bens de que são donos. Compreende sua perpetuidade a possibilidade de sua transmissão, que é até um dos meios de tornar durável a propriedade, por um lapso de tempo indefinido, uma vez que o adquirente é o sucessor do transmitente, a título singular ou universal, recebendo todos os seus direitos sobre a coisa transmitida.
}

Por fim, a propriedade é caracterizada pela elasticidade, ou seja, alterna momentos de plenitude e limitação. Por exemplo, ao adquirir um bem por compra e venda, constitui-se a propriedade plena, contudo, se posteriormente o proprietário oferecê-la em hipoteca, passará aquela a ser limitada, e com o pagamento da dívida a propriedade voltará a ser plena. 
Visto o conceito e as características da propriedade, é importante compreender como se dá a sua aquisição, especificamente quanto à propriedade imobiliária, objeto do presente estudo. Uma das modalidades de destaque é o registro do título, sendo este um ato formal e burocrático. Compreende-se, conforme palavras de Monteiro (2011, p. 120), que a aquisição da propriedade, no direito brasileiro, não se consuma apenas com o acordo de vontades.

A acessão também é um exemplo de forma de aquisição. Aceder significa acrescentar, assim a propriedade de um bem surge no momento em que ele adere a um imóvel cujo proprietário já é definido. A acessão, consoante esclarece Gonçalves (2013, p. 314), depende de dois requisitos: a união de duas coisas, até então separadas, e a natureza acessória de uma delas, uma vez que na acessão predomina o princípio segundo o qual o acessório segue o principal.

Outra forma de aquisição de propriedade é a usucapião, definida por Farias e Rosenvald (2012, p. 396) como "modo originário de aquisição de propriedade e de outros direitos reais, pela posse prolongada da coisa, acrescida dos demais requisitos legais". Ressaltam os autores a originalidade da usucapião, no sentido de que a propriedade usucapida não guarda nenhuma relação com a propriedade anterior.

O fundamento principal da usucapião é a consolidação da propriedade, pois o proprietário relapso, ao abandonar o bem, descumpre o princípio da função social da propriedade, devendo, portanto, ser privado da coisa em favor do possuidor que a protege e dá utilidade, beneficiando interesses particulares e sociais.

Dito isto, faz-se imprescindível descrever os requisitos para efetivação da usucapião. Dentre os requisitos genéricos, ou seja, comuns a todas as modalidades, temos a res habilis, isto é, coisa hábil a ser usucapida. Existem bens que são afastados pela própria lei da aquisição por usucapião, e exemplo disso são os bens públicos sobre os quais a Constituição Federal em seus arts. $183, \S 3^{\circ}$, e 191, parágrafo único, estabelece a impossibilidade de serem usucapidos.

A posse deve ser usucapionem, isto é, deve ser capaz de produzir como efeito a usucapião. Existem posses que não gerarão tal possibilidade, caso da posse de quem é titular do direito. Se a pessoa já tem propriedade, não há como adquiri-la novamente. A posse sem animus domini também não será apta a gerar a usucapião, pois há de se observar se o possuidor tenciona ter o bem para si como se dono fosse.

Ressalta-se como requisito o fato de a posse ser mansa e pacífica. Segundo Diniz (2013, p. 186), tal exigência é atendida quando a posse for:

[...] exercida sem contestação de quem tem legítimo interesse, ou melhor, do proprietário contra quem se pretende usucapir. Se a posse for perturbada pelo proprietário, que se mantém solerte na defesa de seu domínio, falta um requisito para a usucapião. Para que se confirme a usucapião é mister a atividade singular do possuidor e a passividade geral do proprietário e de terceiros, ante aquela situação individual.

A posse deverá ainda ser ininterrupta, tal seja, deverá ser contínua ao longo do lapso temporal exigido pela lei, pois não há como computar o prazo para usucapir um bem a partir de retalhos de tempo nos quais aquele foi devidamente possuído.

Finalmente, como já versado, deve-se respeitar o intervalo de tempo determinado pela lei, o qual difere de acordo com a modalidade de usucapião a ser alegada.

Além dos requisitos genéricos, cada modo de usucapião apresentará peculiaridades que deverão ser observadas, sob pena da não efetivação da propriedade pelo possuidor. 
A usucapião extraordinária, prevista no art. $1238 \mathrm{CC}$, não exigirá nada além dos requisitos genéricos, estabelecendo prazo de 15 anos. Já a ordinária, prenunciada no art. 1242 $\mathrm{CC}$, terá como exigências específicas o justo título e a boa-fé, além do lapso temporal de 10 anos. A boa-fé configura-se quando o possuidor não tem conhecimento de irregularidade que acomete o negócio jurídico realizado para aquisição do bem. O justo título pode ser entendido como um motivo jurídico, como por exemplo, um contrato ou registro na matrícula do imóvel maculado por vícios, os quais acarretarão a invalidação de tais documentos.

Exige-se para a usucapião especial rural e urbana, o que é descrito respectivamente nos arts. 1239 e 1240 do CC, identicamente, a ausência de propriedade sobre outro imóvel, o uso do bem para moradia e prazo de 5 anos. A usucapião rural, no entanto, exige, de forma particular, a produtividade da área agrícola cuja extensão deverá ser de, no máximo, 50 hectares.

A usucapião urbana impõe, especialmente, uma área com limite de $250 \mathrm{~m}^{2}$ e a ausência de requisição de usucapião na mesma modalidade.

Mostra-se importante, ainda, para análise completa do instituto, traçar breves considerações sobre a usucapião coletiva e a indígena.

A primeira se encontra prevista no art. 10 do Estatuto da Cidade, o qual estabelece a possibilidade de um imóvel de no máximo $250 \mathrm{~m}^{2}$ ser usucapido após 5 anos por uma coletividade de baixa renda. A segunda, pormenorizada no art. 33 do Estatuto do Índio, propicia ao indígena possuidor de uma área não maior a 50 hectares usucapi-la após 10 anos.

\section{A Usucapião Conjugal}

Não obstante a existência de todas essas modalidades diversas, o legislador, na Lei $\mathrm{n}^{\circ}$ 12.424, de 16 de julho de 2011, a qual regulamenta o programa "Minha Casa, Minha Vida", adicionou, em seu o artigo $9^{\circ}$, um novo dispositivo no CC, o art. 1240-A, que versa sobre a usucapião conjugal, igualmente chamada de usucapião familiar ou usucapião especial urbana por abandono.

Essa modalidade, como as demais, possui requisitos próprios, quais sejam: a existência de um imóvel urbano comum do casal, tratando-se de uma relação patrimonial surgida do casamento ou união estável (hétero ou homossexual). Deve-se, entretanto, observar o regime de bens aplicável à relação conforme esclarece Farias e Rosenvald (2012, p. 465):

\footnotetext{
O fracionamento da propriedade pode tanto derivar da comunhão universal de bens, como pela aquisição onerosa por um dos cônjuges após o matrimônio pelo regime da comunhão parcial, ou mesmo pela evidência do esforço comum no regime da separação obrigatória. .
}

Essa Além disso, é preciso que ocorra o abandono de lar por parte de um dos cônjuges, e esse abandono deve ser voluntário. Com certeza, trata-se de um dos requisitos mais polêmicos dessa modalidade de usucapião, vez que reabre a discussão sobre a culpa pelo fim do relacionamento.

Exige-se, ainda, o transcurso do tempo de 2 anos, tratando-se do prazo mais curto se comparado às demais usucapiões existentes, devendo o ex-cônjuge permanecer na posse com animus domini e sem a oposição daquele que abandonou o lar.

Ademais, destaca-se que o imóvel deve ser urbano, limitando-se a extensão de até $250 \mathrm{~m} 2$, não podendo o cônjuge que permaneceu no lar ser proprietário de outro imóvel. Ressaltase, por fim, que esse direito não será reconhecido ao mesmo possuidor mais de uma vez. 
Em suma, terá direito a usucapir a parte do imóvel que pertencia ao outro cônjuge ou companheiro aquele que, uma vez abandonado, permanecer no imóvel onde reside a família com exclusividade e sem que seja contestada por aquele que deixou o lar a sua parcela sobre o bem.

Ao estabelecer a usucapião conjugal, o legislador buscou dar aplicabilidade ao direito fundamental à moradia, o qual é garantidor da dignidade da pessoa humana, dado que representa elemento para assegurar o mínimo existencial. Essa modalidade de usucapião visa à proteção ao valor familiar e mostra-se sensível à condição do cônjuge ou companheiro que se manteve forte para seguir com a administração do lar, assumindo solitariamente todos os encargos próprios da função.

Tal instituto fundamenta-se também no princípio da função social da propriedade, conforme esclarece Diniz (2013, p. 194):

A novel usucapião, ao invadir a órbita do direito de família, atende à função social da propriedade por garantir a moradia daquele que exerce a posse do imóvel, protegendo a comunidade familiar, apesar de violar normas sobre propriedade e regime matrimonial.

O instituto, portanto, fomenta a função social da propriedade na medida em que possibilita a manutenção da estrutura familiar, objetivando garantir moradia adequada para aqueles que mantiveram a relação afetiva e conduziram a administração do lar.:

\section{Das Principais Controvérsias da Usucapião Conjugal}

Não obstante o caráter benévolo do instituto, é possível identificar prováveis atecnias e inconstitucionalidades que o acometem.

Inicialmente, pode-se indagar sobre o sentido da palavra "direta" empregada no art. 1240-A, o qual estabelece que o cônjuge ou companheiro abandonado deve exercer posse direta sobre o imóvel como se aquele que deixou o lar ainda exercesse uma posse indireta, sendo tal concepção incompatível com o sentido de abandono da propriedade, haja vista que poderia significar algum resquício de interesse por parte daquele que foi embora. Assim, esclarece Diniz (2013, p. 195) que "o conceito de posse direta referido no art. 1240-A do Código Civil não coincide com a acepção empregada no art. 1197 do mesmo Código”.

Outro ponto importante e causador de controvérsia é a definição de "abandono de lar”, já que é difícil compreender quando este estaria configurado. Investiga-se ainda se o cônjuge ou companheiro que optou por deixar o lar, mas que continua em contato com os filhos, mesmo longe da antiga residência, enquadrar-se-ia na situação de larífugo. Compreende-se que tal situação não configuraria abandono, pois sair do antigo lar e reconstruir nova vida, sem, no entanto, deixar de dar assistência aos filhos, é uma escolha particular que não pode ser tolhida por mandamentos retrógrados, os quais engessam a liberdade dos indivíduos.

Conexo com tal problemática, discute-se uma provável afronta à Emenda Constitucional no 66/10, conforme assentam Farias e Rosenvald (2012, p. 465):

\footnotetext{
O abandono do lar por parte de um dos conviventes - certamente este é o requisito mais polêmico da usucapião pró-família. Afinal a EC no 66/10 revogou todas as disposições contidas em normas infraconstitucionais alusivas à separação e às causas da separação, como por exemplo, o artigo 1573 do Código Civil que elencava dentre os motivos caracterizadores da impossibilidade de comunhão de vida, "o abandono voluntário do lar conjugal” (inciso IV). Com a nova redação conferida ao art. 226, par. $6^{\circ}$, da CF [...] não apenas são superados os prazos estabelecidos para o divórcio, como é acolhido o princípio da ruptura em substituição ao princípio da culpa, preservando-se a vida privada do casal.
} 
Não há dúvidas, portanto, sobre inconstitucionalidade do instituto, conforme esclarece Luciana Silva (2011, p. 3)::

O Direito de Família brasileiro, nem mesmo sob a máscara de função social da propriedade, admite a intervenção estatal desarrazoada na vida privada, sob a pena de violação da dignidade da pessoa humana. No mais, os princípios constitucionais possuem função de revelar e unificar o Ordenamento Jurídico, não permitindo afronta por normas infraconstitucionais. Assim, fazer da culpa a fênix que surge das cinzas pelo Usucapião dito pró-Família ofende a ordem constitucional posta, a qual é baseada na afetividade e não mais no patrimônio ou na tutela da moral..

Se há duvidas para definir o abandono, é questionável o momento que se deve iniciar a contagem do prazo de 2 anos. Questiona-se se deve ser contabilizado o período de abandono anterior à vigência da lei. Após discussões doutrinárias, entendeu-se que sua contagem deve começar a partir da vigência da Lei no 12.424, ou seja, 16 de junho de 2011, segundo esclarece Gama e Marçal (2013, p. 266-267):

Seria possível que pessoa que já preenchesse os requisitos legais para o reconhecimento da usucapião conjugal pudesse se valer no ano de 2012 de tal modalidade de aquisição de propriedade?

Impõe-se a resposta negativa. Qualquer interpretação em sentido contrário violaria o princípio da segurança jurídica ao surpreender o ex-cônjuge ou ex-companheiro a quem se impute o abandono do lar, além de implicar em retroatividade da lei ora editada. Tal raciocínio fora adotado por ocasião da instituição da usucapião especial urbana, que teve o seu prazo reduzido pela Constituição Federal de 1988, em que E. STF entendeu por não ser computado o prazo anterior a lei.

Assim, o prazo bienal deve ser contado a partir da data da entrada em vigor da Lei 12.424/2011, o que ocorrera em 16.06.2011. Tal orientação restou consagrada no Enunciado 498 aprovado na V Jornada de Direito Civil do Conselho da Justiça Federal.

Ademais, um lapso temporal tão abreviado talvez fira o princípio da igualdade, pois as demais modalidades de usucapião garantem períodos mais alargados. Então, por que exigir da usucapião conjugal dilação tão curta, se tal modalidade envolve questões extremamente subjetivas como sentimentos e dores, as quais não podem ser refletidas ou, até mesmo, resolvidas em 2 anos?

Ainda quanto à contagem do prazo, Gama e Marçal (2013, p. 262) esclarecem que se se observar apenas a literalidade da norma, aquele só começaria a ser contado a partir do divórcio ou da comprovação efetiva da dissolução da união estável, uma vez que, por força do art. 197 do CC/2002, não corre prazo prescricional durante a sociedade conjugal. Entretanto, segundo os coautores, tal interpretação mostra-se inadequada, pois o referido artigo foi elaborado para aplicação durante a existência do laço matrimonial. Assim, uma vez quebrado o vínculo, mesmo que com a separação de fato, não há mais harmonia a ser preservada, pois a relação já se encontra desfeita. Logo, a contagem do prazo deve ser iniciada logo que o cônjuge ou companheiro sai de casa e não mais retorna.

Conforme ainda apresentam Gama e Marçal (2013, p. 262), este foi o entendimento positivado pela V Jornada de Direito Civil, segundo a qual “[...] a condição de ex-cônjuge ou de ex-companheiro corresponde à situação fática da separação, independente de divórcio.”.

Outra aparente ofensa à igualdade está relacionada à possibilidade de efetivação de tal usucapião apenas para imóvel urbano. O legislador, portanto, mostrou-se omisso com relação à esfera rural.

É sabido, entretanto, que o princípio da isonomia preconiza a igualdade de condições aos sujeitos que estejam em idêntica situação e só autoriza tratamento distinto quando houver 
elementos que coloquem um indivíduo em condição mais vulnerável, quando comparado aos demais. Neste sentido, Marinela (2013, p. 47) leciona:

\begin{abstract}
Este princípio tem um conceito maravilhoso, quase uma poesia. Isonomia significa tratar os iguais de forma igual e os desiguais de forma desigual, na medida de suas desigualdade. Todavia, a dificuldade é fixar quais são os parâmetros e definir quem são os iguais ou os desiguais e, o que é ainda pior, qual é a medida da desigualdade.

Com o propósito de facilitar a aplicação desse princípio, verificando se há ou não a sua violação, é possível utilizar-se de dois elementos: primeiro, identificar qual é o fator de discriminação e, em seguida, verificar se esse fator de exclusão está ou não de acordo com o objetivo da norma. Quando o fator de discriminação utilizado no caso concreto estiver compatível com o objetivo da norma, não há violação do princípio da igualdade e a exclusão é válida. De outro lado, o inverso não é verdadeiro, havendo desobediência à isonomia se a regra de exclusão estiver incoerente com a norma.
\end{abstract}

Logo, a localização do domicílio de uma pessoa não pode ser critério plausível para um tratamento diferenciado. Para que seja estabelecida uma discriminação pela Lei, deve existir uma justificativa lógica, o que não se observa nesta exigência descabida proposta na usucapião conjugal que em vez de efetivar o objetivo da norma, afasta sua aplicação para as famílias rurais, as quais estão igualmente sujeitas às crises familiares e, por consequências, ao abandono familiar.

Logo, diante de mais essa inconstitucionalidade, pode-se propor a utilização do controle de constitucionalidade difuso, pelo qual o juiz, analisando a particularidade do caso concreto, decretará a inconstitucionalidade incidental e admitirá a usucapião para um imóvel rural, uma vez que, segundo Mendes (2012, p. 1171):

O controle de constitucionalidade concreto ou incidental, tal como desenvolvido no direito brasileiro, é exercido por qualquer órgão judicial, no curso de processo de sua competência. A decisão, que não é feita sobre o objeto principal da lide, mas sim sobre questão prévia, indispensável ao julgamento do mérito, tem condão apenas de afastar a incidência da norma viciada.

Discute-se, ainda, que a limitação do uso desse direito em uma única situação parece injustificada, pois nada impede que uma pessoa se veja nessa condição mais de uma vez. Limitar o indivíduo a novo casamento parece demonstrar o caráter retrógrado do instituto, o que deverá ser objeto de análise também pelo controle difuso para que, no caso concreto, desconsidere-se sua aplicação.

\title{
Conclusão
}

Ante o exposto, foram constatados alguns equívocos de natureza técnica por parte do legislador, além de aspectos de inconstitucionalidade no art. 1240-A do CC.

Há expressões de difícil compreensão que foram destacas no presente trabalho. Imperioso, portanto, que se substitua a palavra "direta" por um vocábulo adequado, tal como contínua ou atual.

Quanto à expressão “abandono de lar”, seria imprescindível que o artigo orientasse em que circunstâncias tal fato estaria configurado para que não sejam abertas margens para interpretações que fazem ressurgir questões ultrapassadas pelo direito brasileiro e que repercutem em inconstitucionalidades que violam a liberdade para que o indivíduo reja sua vida familiar.

Além disso, o prazo encurtado de dois anos comparado às outras modalidades de usucapião demonstra a total falta de razoabilidade do instituto. Talvez uma dilação temporal 
mais alargada seja necessária até mesmo para que os problemas familiares, causadores de grande sofrimento, possam ser pacificados.

Por fim, demonstrando clara ofensa ao princípio da igualdade, o legislador previu que o mencionado instituto só seria efetivado quando se tratasse de imóveis urbanos, gerando, assim, uma lacuna quanto aos imóveis rurais. Nesse sentido, entendendo-se pela inconstitucionalidade, propõe-se de imediato a utilização do controle de constitucional difuso em que o juiz, analisando o caso concreto, decretaria a inconstitucionalidade incidental e admitiria a usucapião conjugal para o imóvel rural. Tal controle também poderá ser utilizado para afastar aplicação do $\S 1^{\circ}$, art. 1240-A, o qual limita a aplicação dessa modalidade de usucapião a uma única oportunidade.

Diante dessas inconstitucionalidades, propõe-se uma total reformulação do artigo para eliminá-las, ampliando o alcance da norma para os imóveis urbanos e garantindo a possibilidade de sua incidência em mais de uma ocasião.

\section{REFERÊNCIAS}

BRASIL. Constituição da República Federativa do Brasil: promulgada em outubro de 1988. Brasília. Senado Federal, 2012.

CHAVES, José Vander Tomaz. Da função social dos contratos no direito brasileiro ante a disciplina jurídica da propriedade funcionalizada. 2005. Tese [Mestrado em Direito]. Universidade Federal do Ceará, Fortaleza, 2005. 200 f.

DINIZ, Maria Helena. Curso de Direito Civil brasileiro: Direito das Coisas. 28. ed. v. 4. São Paulo: Saraiva, 2013.

FARIAS, Cristiano Chaves de; ROSENVALD, Nelson. Curso de Direito Civil: reais. 8. ed. v. 4. Salvador: JusPODIVM, 2012.

GAMA, Guilherme Calmon Nogueira; MARÇAL, Thaís Boia. Aspectos polêmicos da

“Usucapião Conjugal”: questões afetas ao art. 1.240-A do Código Civil brasileiro. Revista de Direito Privado, São Paulo, v. 54, p. 257-277, abr./jun. 2013.

GONÇALVES, Carlos Roberto. Direito Civil brasileiro: Direito das Coisas. 8. ed. v. 5. São Paulo: Saraiva, 2013.

LOURDES, José Costa; GUIMARÃES, Taís Maria Lourdes Dolabela. Novo Código Civil comentado. 2. ed. rev. atual. e ampl. Belo Horizonte: Del Rey, 2003.

MARINELA, Fernanda. Direito Administrativo. 7. ed. Niterói: Impetus, 2013.

MARMELSTEIN, George. Curso de direitos fundamentais. 2. ed. São Paulo: Atlas, 2009.

MENDES, Gilmar Ferreira; BRANCO, Paulo Gustavo Gonet. Curso de Direito

Constitucional. 7. ed. São Paulo: Saraiva, 2012.

MIRANDA, Francisco Cavalcante Pontes de. Tratado de Direito Privado. 3. ed. Tomo XI. São Paulo: Borsoi, 1970. 
MONTEIRO, Washigton de Barros; MALUF, Carlos Alberto Dabus. Curso de Direito Civil: Direito das Coisas. 41. ed. v. 3. São Paulo: Saraiva, 2011.

PEREIRA, Caio Mário da Silva. Instituições de Direito Civil: Direitos reais. 21. ed. v. 4. Rio de Janeiro: Forense, 2013.

SILVA, Luciana Santos. Uma nova afronta à carta constitucional: usucapião pró-família. Disponível em: <http://www.ibdfam.org.br/_img/artigos/Usucapi\%C3\%A3o\%20Luciana.pdf>. Acesso em: 2 dez. 2011.

\section{ADVERSE POSSESSION BY MARRIAGE LINK IN BRAZILIAN LAW}

Abstract: The theme of this work is directly related to one of the modes of acquiring property. Marital prescription gained prominence via article 1240-A of Brazil's Civil Code (CC), but has many controversial aspects, which are analyzed here.

Keywords: Social Function. Home abandonment. Property. Adverse possession. Marriage.

Data de recebimento: nov/2014 - Data de aprovação: mar/2015 